\title{
Predicting the Perception of SMEs on the Selection of Bank Decision in Pakistan: A Partial Least Square (PLS) Model
}

\author{
Zafar Iqbal \\ Assistant Professor \\ MUST Business School, Mirpur University of Science and Technology (MUST) \\ Mirpur Azad Jammu and Kashmir Pakistan \\ Dr. Saima Batool \\ Associate Professor / HoD, Department of Business Administration \\ Nur International University, Lahore \\ saima.batool@niu.edu.pk
}

Dr. Muhammad Khalique

Associate Professor/Director, MUST Business School, Mirpur University of Science and Technology (MUST), Mirpur Azad Jammu and Kashmir, Pakistan

\author{
Dr. Mushtaq A. Sajid \\ Professor, University of Kotli, Azad Jammu and Kashmir
}

\begin{abstract}
:
The main objective of this study was to examine the main factors which may have influence on the bank selection decision in Pakistan. Quality of service, quality of service provider, interaction dimensions and relationship image recommendations experience were employed as independent variables while the bank selection decision SMEs was used as a dependent variable. The data were gathered through structured questionnaire survey. A total of 300 questionnaires were distributed to the targeted respondents while 223 were involved in the study. The respondents were selected through purposive sampling technique. Four research hypotheses were established. Smart Partial Least Square (PLS) 3 was used to test the proposed research hypotheses. The empirical findings of this study showed that the four research hypotheses were supported. This is the first study in Pakistan to address this issue.
\end{abstract}

Keywords: Quality of service, quality of service provider, interaction dimensions relationship image recommendations experience, bank selection decision, SMEs, Pakistan

\section{Introduction}

In contemporary business environment, the banking sector is considered as an important financial service provider and it has very significant role in the development and growth of national economy. There is no doubt that the banking sector plays a vigorous role in various forms at globe and without a sound and effective banking sector no healthy economy can possible. In a knowledge based economy banking sector provides a well-established mechanism to do business. It 
gives monetary administrations to business enterprises to complete their business transactions. Moreover, the act of intermediation the funds among the different participants or pillars of economy make the flow of funds smooth, for example they collect the surplus saving and make them possible for investment activities (Khalique, Shaari, Abdul, Isa, \& Samad, 2013; Kumari, 2017). Banks helps to boost the economic activity in country by properly placing the savings of clients among different sectors suffering from deficits. Effective working of these institutions adds to monetary development (Khalique, Shaari, \& Isa, 2014; King \& Levine, 1993).

In a knowledge-based economy, the health of the economy is closely associated with the soundness of its financial system. Banking system is one of the most important participants in any financial system because of the very nature of its functions and services. In modern economy the bank selection criteria is considered as one of the most important strategy for the success of banking sector. In this connection, the banking sector requires to understand the perception about bank selection criteria of their existing and potential customers (Kaynak \& Kucukemiroglu, 1992; Rashid, Bhuiyan, \& Nishat, 2012). In modern business environment the mounting competitiveness in the banking sector and comparison of services offered by the banking industry (Holstius \& Kaynak, 1995; Khalique et al., 2013). Moreover, they argued that the banking sector is required to recognize and identify the factors determining the foundation upon which customers select among providers of the financial services. Many researchers such as (Blankson, Omar, \& Cheng, 2009; Denton \& Chan, 1991; Rao \& Sharma, 2010) argued that customers are always consider factors to choose the bank for financial services. Significant related literature clearly showed that many studies have been conducted in developed economies selecting a bank and their results might and might not be fully appropriate to other countries, because of legal and economic environment and the differences in culture. Rao and Sharma (2010) stated that a number of determining factors which bears a significant role in selecting a bank in one country may prove to be insignificant in another country. Therefore, there was a great need to address this issue in Pakistani context.

\section{Literature Review}

In Pakistan, banking sector plays a very important role in the development and growth of various sectors such as manufacturing industry, service industry, employment, financing large-scale industry and small-scale industry. In Pakistan, the banking sector has evident that it has undergone considerable changes from the time when the government of Pakistan declared its policy to privatize commercial banks. As a result, Pakistan motivated in the direction of liberalization and financial sector deregulation in the year 1990 in order to implement structural reforms agenda and to fortify financial system. In a competitive business environment, quality and effective services of banking sector is very crucial factors for the progress and development of banking sector in Pakistan as well as at globe. Subsequently, Pakistani banks are offering an enlarged variety of services to accommodate the need and demand of customers. As a result, this scenario has initiated privatization of commercial banks and introduction of the new ones starting from the private sector to create a marketbased banking structure (Akhtar \& Nishat, 2002). In Pakistan, the banking sector has 
observed an enormous change during the last one and a half decade. Moreover, the financial environment is promptly moving forward and customers are becoming more sophisticated and demanding, it is becoming important for banking sector to determine such factors that are appropriate to the process of the customers' selection of the banks (Boyd, Leonard, \& White, 1994).

\section{SMEs and Banking Sector in Pakistan}

Small and medium enterprises (SMEs) plays very important role in the development and growth of national economy of all countries in the world (Khalique, Bontis, Shaari, Yaacob, \& Ngah, 2018). SMEs performs in many ways for the progress and prosperity of Pakistan's economy such as job creation, GDP, export, innovation and uplifting the living standards of people (Khalique, Bontis, Jamal, \& Isa, 2015). In Pakistan, the SMEs constitute over 90 percent of estimated 3.2 million businesses units with the contribution of 30 percent in GDP and approximately 25 percent in export earning. Due to the significant importance of SMEs, the State Bank of Pakistan has started focusing on this sector from the period of 2004-2006 with financing of Rs.408 billon reached at 17 percent of total private sector financing in 2006. Unfortunately, due to economic slowdown since 2007-2008 SMEs are facing severe challenges, less profitable and high risk of failure. In 2013, the State Bank of Pakistan has again made efforts and play supportive role by increasing financing to SMEs. In December 31, 2016, total number of SME borrowers stood at around 177,000 and outstanding SME financing of banks/ development finance institutions was Rs401 billion, showing an increase of 31 percent on year-on-year basis. The share of SME lending as percentage of total credit to private sector was 9 percent as of total private sector credit (Zaidi, 2018).

Currently financing to small and medium enterprises is getting more exigent for banks. SMEs need funding for the expansion of the business and for taking an initiative. Lots of official procedures and processes involving the preparation and evaluation of viability reports are there. Loans are being offer by the banks to SMEs but major of the banks limited their selves to give credit to those SMEs who have had stepped up and are in developing stage. The majority of the banks thoughtful SMEs as this portion are in enormous development to be more important for banks. In Pakistan a few years back financing methodologies were changed to give credit to SMEs on easy and flexible conditions. There is no-doubt that the Pakistani banks support crediting to SMEs by giving them chances of development, SMEs is a developing part; banks advance SMEs in the way they are advancing medium ventures however maintaining a strategic distance from little undertakings. Little undertakings have less open door for the development than the medium endeavors. Presently, both little and medium endeavors and the medium undertakings are engaged similarly by banks to be grateful. SMEs in Pakistan are more than the corporate businesses, so SMEs have got to be potential clients for banks to serve.

\section{Theoretical Framework and Hypotheses Development}

During extensive related literature review, it was found that a few studies have been conducted on selection criteria of banks in Pakistan. For example, (Rehman \& Ahmed, 2008; Saad, 2012; Sadiq, Khan, \& Abdur, 2014; Siddique, 2015)studied the main factors of a bank selection decision by customers. Hafeezur and Saima (2008) 
investigated privatized and nationalized banks in Pakistan to find out the determinants of customers to bank selection decision. The study has taken responses from customers of private and nationalized banks working within Lahore city.In similar vein(Zulfiqar, Arshad, Fareed, Shahzad, \& Hussain, 2014)have conducted their study on the customer's behavior towards the bank selection in Sahiwal Division, Pakistan. The results of the study revealed important factors that influence bank selection criteria are convenience, quality of services and price and cost. As these factors contribute towards the selection of banks by customer so, the management of nationalized, privatized and privates banks should keep in view these important factors while making marketing strategies.However, none of them has studied the bank selection criteria of customers in Pakistan and Azad Kashmir. Therefore, this study is particularly intended to examine the determinants of customers' bank selection in major cities of Pakistan and Azad Kashmir. On the basis of the previous studiesthis study used quality of service (QS), quality of service provider (QSP), interaction dimensions (ID) and relationship image recommendations experience (RIRE) as most important components that may effect on the bank selection decision (BSD) of customers. The quality service provider was based on politeness, quick response, complete information, friendly attitude etc. Kheng, Mahamad, Ramayah, and Mosahab (2010) sated that the service quality can enhance customer loyalty and it plays a major role to maintain reliability, empathy and assurance. Saad (2012) argued that the quality of services is mainly based on skills, responsiveness, and efficiency of bank employees to their customers. Interaction dimension was based on relationship with banks, bonding forces, easy access etc., while relationship image recommendations experience encompasses on good brand, advertising, image, helping, commitments etc. Finally, the banks selection decision was on the location, fee charges, services, confidentially etc.

Subsequently,on the basis of literature review and empirical evidences the following hypotheses were formulated for the study to find the objective of the study.

Hypothesis 1: Quality of service (QS) has positive impact on the bank selection decision (BSD) of Pakistani SMEs.

Hypothesis 2: Quality of service provider (QSP) has positive impact on the bank selection decision (BSD) of Pakistani SMEs.

Hypothesis 3: Interaction dimensions (ID) has positive impact on the bank selection decision (BSD) of Pakistani SMEs.

Hypothesis 4: Relationship image recommendations experience (RIRE) has positive impact on the bank selection decision (BSD) of Pakistani SMEs.

\section{Research Methodology}

This cross sectional study was designed with quantitative technique. The primary data were gathered through structured questionnaire survey. Four independent variables namely, quality of service (QS), quality of service provider (QSP), interaction dimensions (ID) and relationship image recommendations experience (RIRE) while the bank selection decision (BSD) of SMEs was employed as dependent variable. 


\section{Research Instrument and Data Collection}

The required primary data for this study were collected through structured questionnaire survey. The survey was based on five point Likert Scale where $(1=$ strongly disagree and $5=$ strongly agree). The questionnaire items were clear and comprehensible. To measure the constructs of independent variables and depended variable the scale of 73 items were adopted from (Almossawi, 2001; Devlin \& Gerrard, 2004; Gerrard \& Cunningham, 2001; Rao \& Sharma, 2010; Thwaites \& Vere, 1995) and minor amendments were made where required. To select the targeted respondents of this study, purposive sampling technique was used. The population or sampling unit in this study was the decision-making level or higher rank of employee from SMEs from the major cities of Province of Punjab Pakistan and Mirpur Division Azad Jammu and Kashmir. This group of respondents will be able to provide valid and accurate view of their organizations. SMEs from the major cities of province Punjab such as, Rawalpindi, Lahore, Gujranwala, Sialkot, Wazriabad, Lala Musa, Gujrat and Faisalabad and from Mirpur division Azad Jammu and Kashmir namely Kotli, Bhimber and Mirpur were targeted to involve in this study. A total of 300 structured questionnaire survey were distributed through personally administrated approach to the targeted respondents where 223 respondents who participated were from the aforementioned cites of the Province of Punjab and Mirpur Division. The response rate of valid return questionnaire was $70.3 \%$, which was considered as satisfactory. In this study, 223 respondents were involved for data analysis, which fulfills the threshold of sample size larger than 30 and less than 500 are appropriate for most research (Sekaran \& Bougie, 2016).

\section{Results}

The empirical findings of this study were extracted from primary data. The gathered data were grasp the perception of the respondents about the employed variables of this study. Before data analysis, the collected data were cleaned and screened by using outliers, sleekness and kurtosis. The results found that the data are normally distributed and can be used for further analysis. This study employed Partial Least Squares (PLS) path modeling using Smart PLS 3.0 software to perform data analysis. A PLS model is normally analyzed and interpreted in two stages (Hair Jr, Hult, Ringle, \& Sarstedt, 2016) the measurement model and structural model to test the proposed research hypotheses.

\section{Measurement Model}

In Partial Least Squares (PLS) path modeling measurement model is used to check the reliability and validity of the primary data. Götz, Liehr-Gobbers, and Krafft (2010) argued that there are three step procedures for evaluating the measurement model namely, individual item reliabilities, convergent validity and discriminant validity. The criteria of indicator loadings vary, for example (Joe F Hair, Ringle, \& Sarstedt, 2011; Joe F Hair, Sarstedt, Ringle, \& Mena, 2012) The criteria of indicator loadings (factor loadings) should be higher than 0.70 (Joe F Hair et al., 2011; Joe F Hair et al., 2012) while J. F. Hair, William, Barry, and Anderson (2010) and Chin (1998) argued that the loading value of 0.5 is regarded as acceptable, the variables with loading value of less than 0.5 should be dropped. To follow the aforementioned criteria, this study used cut-off value for factor loadings at near to 0.70 as being minimum 
threshold. The assessment of the convergent validity of each construct is very important. It refers to the magnitude to which item truly represents the intended latent construct and certainly correlate with other measures of the same latent construct (Fernandes, 2012; Joe F Hair et al., 2011). The convergent validity was measured by examining the average variance extracted (AVE) of more than 0.5 and composite reliability (CR) of 0.70 or above were considered acceptable (Chin, 1998). As shown in Table 1, all items load a range from 0.60 to 0.83 into their respective constructs and the values of AVE and CR were considered acceptable.

Table 1: Results of the Measurement Model

\begin{tabular}{|c|c|c|c|c|c|}
\hline Constructs & Items & Loading & AVE & $\mathbf{C R}$ & $\alpha$ \\
\hline \multirow{7}{*}{ Quality Service } & Item 1 & 0.784 & 0.518 & 0.882 & 0.849 \\
\hline & Item 2 & 0.712 & & & \\
\hline & Item 3 & 0.739 & & & \\
\hline & Item 4 & 0.716 & & & \\
\hline & Item 5 & 0.624 & & & \\
\hline & Item 6 & 0.659 & & & \\
\hline & Item 7 & 0.788 & & & \\
\hline \multirow[t]{3}{*}{ Quality Service Provider } & Item 1 & 0.688 & 0.652 & 0.848 & 0.735 \\
\hline & Item 2 & 0.785 & & & \\
\hline & Item 3 & 0.763 & & & \\
\hline \multirow[t]{5}{*}{ Interaction Dimension } & Item 1 & 0.814 & 0.544 & 0.855 & 0.791 \\
\hline & Item 2 & 0.772 & & & \\
\hline & Item 3 & 0.675 & & & \\
\hline & Item 4 & 0.770 & & & \\
\hline & Item 5 & 0.642 & & & \\
\hline \multirow{6}{*}{$\begin{array}{l}\text { Relationship Image } \\
\text { Recommendations Experience }\end{array}$} & Item 1 & 0.709 & 0.538 & 0.874 & 0.828 \\
\hline & Item 2 & 0.671 & & & \\
\hline & Item 3 & 0.835 & & & \\
\hline & Item 4 & 0.710 & & & \\
\hline & Item 5 & 0.719 & & & \\
\hline & Item 6 & 0.744 & & & \\
\hline \multirow[t]{9}{*}{ Bank Selection Decision } & Item 1 & 0.699 & 0.541 & 0.913 & 0.893 \\
\hline & Item 2 & 0.691 & & & \\
\hline & Item 3 & 0.715 & & & \\
\hline & Item 4 & 0.740 & & & \\
\hline & Item 5 & 0.754 & & & \\
\hline & Item 6 & 0.743 & & & \\
\hline & Item 7 & 0.780 & & & \\
\hline & Item 8 & 0.648 & & & \\
\hline & Item 9 & 0.832 & & & \\
\hline
\end{tabular}

The discriminant validity is considered as a next step of the measurement model. Joe F Hair et al. (2011) stated that discriminant validity specifies that each latent 
construct's AVE should be higher than the construct's highest squared correlation with other latent constructs. The off-diagonal values are the correlations between the latent constructs and the diagonals are square values of AVEs. The discriminant validity criteria were assessed according to Fornell and Larcker (1981) loading and cross loading. As shown in Table 2 and Table 3 Discriminant Validity of constructs (Fornell and Larcker Criteria) were examined and found that the validity was established.

\begin{tabular}{lccccc} 
Table 2: Discriminant Validity (Fornell and Larcker Criteria) \\
\hline Constructs & BSD & ID & QS & QSP & RIRE \\
\hline Bank Selection Decision (BSD) & $\mathbf{0 . 7 3 5}$ & & & & \\
Interaction Dimension (ID) & 0.450 & $\mathbf{0 . 7 3 7}$ & & & \\
Quality Service (QS) & 0.557 & 0.368 & $\mathbf{0 . 7 2 0}$ & & \\
Quality Service Provider (QSP) & 0.541 & 0.486 & 0.332 & $\mathbf{0 . 8 0 7}$ & \\
Relationship Image Recommendations & 0.721 & 0.357 & 0.476 & 0.474 & $\mathbf{0 . 7 3 3}$ \\
Experience (RIRE) & 0.721
\end{tabular}

Notes: *The off-diagonal values are the correlations between the latent constructs and diagonal are square; values of AVEs

In PLS, Heterotrait-Monotrait Ratio (HTMT) is also considered another means of determining the discriminant validity of a model. Henseler, Ringle, and Sarstedt (2015) argued that a latent construct has discriminant validity when its HTMT ratio is below 0.825 . As presented in Table 4, the HTMT ratios of all the constructs used in the model were well below the threshold value of 0.825 which indicated that the employed constructs used in the model have established discriminant validity. Multicollinearity test was also employed and found that the Variance inflation factor (VIF) results for the independent variables were less than 2 indicating that there is no multicollinearity problem for the analysis (Henseler et al., 2015).

Table 3: Discriminant Validity Heterotrait-Monotrait Ratio (HTMT)

\begin{tabular}{llllll}
\hline Constructs & BSD & ID & QS & QSP & RIRE \\
\hline Bank Selection Decision (BSD) & & & & & \\
Interaction Dimension (ID) & 0.515 & & & & \\
Quality Service (QS) & 0.579 & 0.429 & & & \\
Quality Service Provider (QSP) & 0.659 & 0.553 & 0.402 & & \\
R/s Image Rrecom. Exp. (RIRE) & 0.819 & 0.420 & 0.515 & 0.596 & \\
\hline
\end{tabular}

Therefore, based on the results, a good degree of reliability and validity is achieved and the latent variables are valid and reliable. The schematic of measurement model represents the theoretical model and construct validity of this study which is showed in Figure1. 
Figure 1: Theoretical Model and Construct Validity

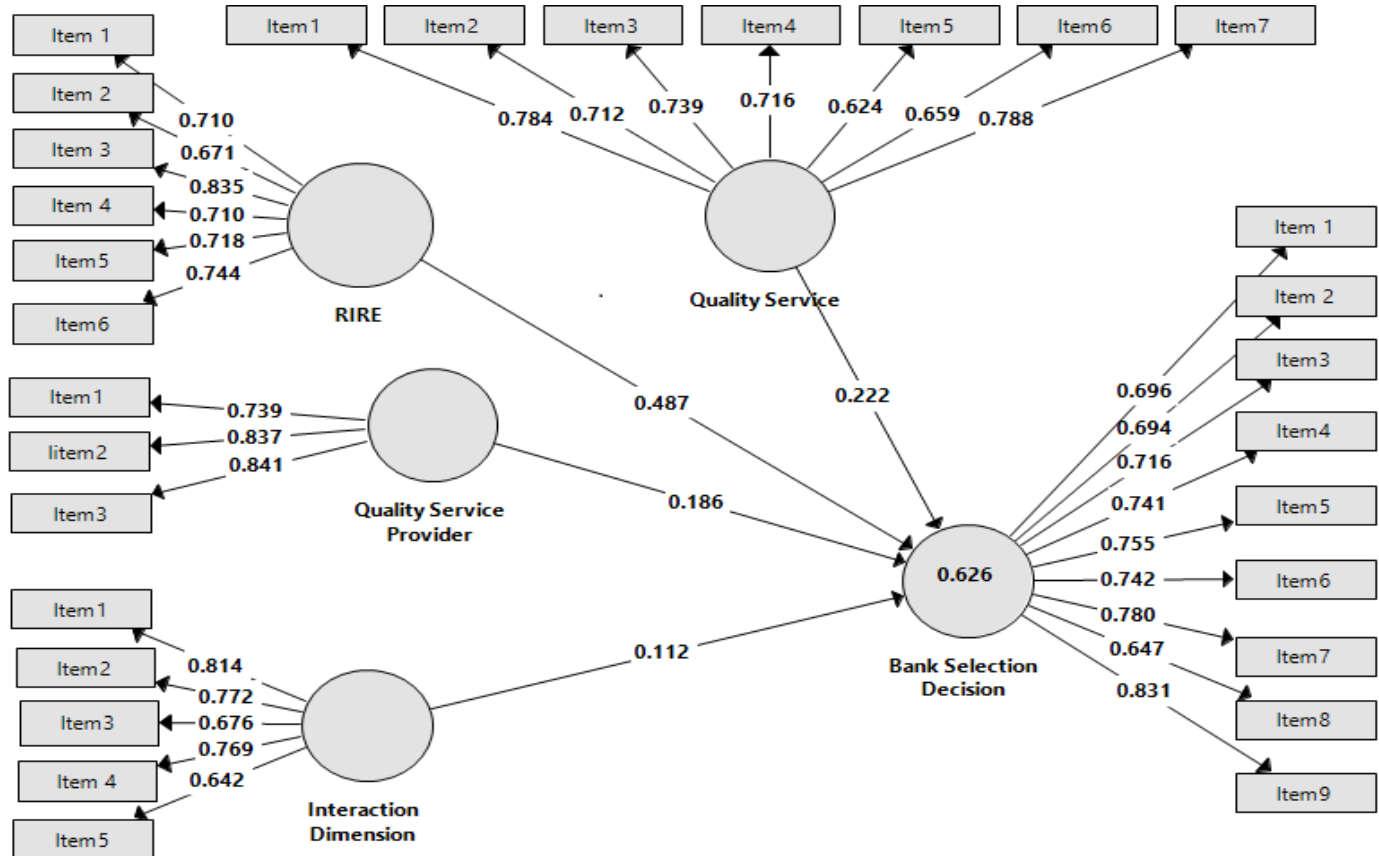

Structural Model

In PLS the structural model demonstrates the relationships between independent variables with dependent variable that were hypothesized the in research model. In this model the results were achieved through 5,000 bootstrapping (Joe F Hair et al., 2011; Joe F Hair et al., 2012; Hair Jr et al., 2016). The significance of path approximate and the variance explained $\left(R^{2}\right)$ of the endogenous construct were applied to determine the goodness of the model (Chin, 2010). The significance of all path estimates and the total variance explained by four independent variables were $\left(R^{2}\right) 64.7$ percent. The minimum criterion of acceptable level for $\mathrm{R}$-square is 0.10 (Falk \& Miller, 1992). Based on the aforementioned criteria, it can be concluded that the bank selection decision have an adequate level of R-squared values. As shown schematically in Figure 2, the paths' significance level, and the results of hypotheses testing were tabulated in Table 4 showed that all hypotheses were supported.

Figure 2: Structural Model 


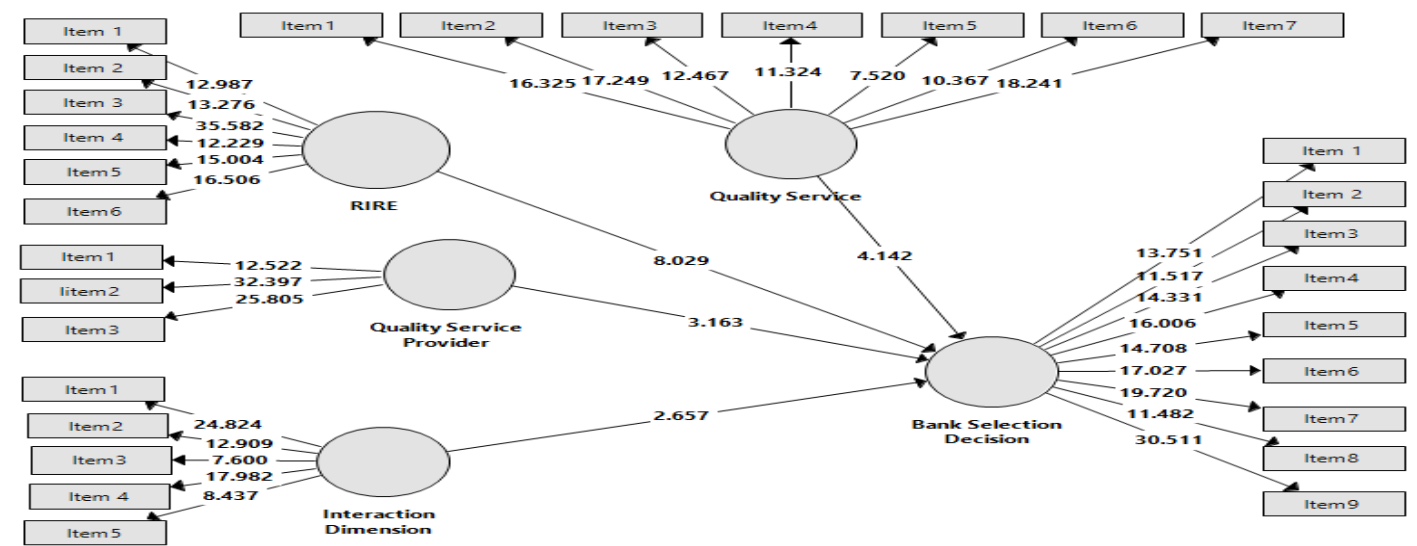

Table 4: Path Coefficient and Summary of Hypotheses Testing

\begin{tabular}{llcccc}
\hline Hypotheses & Relationship & & Coefficient & t- value & Supported \\
\hline $\mathrm{H} 1$ & $\begin{array}{l}\text { Quality of service } \\
\text { Selection Decision } \\
\text { Quality Service Provider }\end{array}$ & Bank & 0.222 & 4.142 & Yes \\
H2 Bank & 0.186 & 3.163 & Yes \\
$\mathrm{H} 3$ & $\begin{array}{l}\text { Selection Decision } \\
\text { Interaction Dimension }\end{array}$ & $\begin{array}{l}\text { Selection Decision } \\
\text { Relationship image recommendations } \\
\text { experience > Bank Selection Decision }\end{array}$ & 0.487 & 8.029 & Yes \\
$\mathrm{H} 4$ & & & 0.122 & 2.657 & Yes \\
\hline
\end{tabular}

Note: $P<0.05$

The findings of Table 4 and Figure 2 clearly showed that the proposed research hypotheses were supported. Quality of service, quality of service provider and interaction dimension were found positively and significantly related to bank selection decision $(\beta=0.222, t=4.142, P<0.05),(\beta=0.186, t=3.163, P<0.05)$, and $(\beta=$ $0.122, t=2.265, P<0.05)$, respectively. Hypothesis 4 reported that relationship image recommendations experience was established positively and significantly related to bank selection decision $(\beta=0.487, t=8.029, P<0.05)$. In this research, relationship image recommendations experience appeared as the most significant and important variable to bank selection decision while interaction dimension has less relationship.

\section{Conclusion Limitations and Future Recommendations}

The prime objective of this study was to find the major factors which are used to select the banks in Pakistan and Azad Jammu and Kashmir. This study is unique in nature and it has shed light on the behavior of SMEs to select the services of banking sector. In this empirical study, four independent variables namely, quality of service (QS), quality of service provider (QSP), interaction dimensions (ID) and relationship image recommendations experience (RIRE) as most important components were employed to examine their contribution towards the selection of bank's services in Pakistan. The study produced interesting findings and showed that the relationship image recommendations experience (RIRE) was appeared as the most important and significant contributor to select bank services in Pakistan while interaction dimension was the less predictor among all variables. 
The contributions of this study are twofold: first, theoretical contribution, the empirical results of this study make a modest input to the SMEs and the selection of Banking in Pakistani context. In Pakistani context there has been no study conducted before this empirical effort. The current effort fills the existing vacuum and provides important insight into the bank selection criteria and patronage factor of SMEs in Pakistan. Second, managerial implications,this empirical study offers a lot of recommendations for banking sector. In Pakistan SMEs plays very crucial role for the development and growth of national economy. Despite the significant contribution in various sectors, SMEs are still facing many challenges. This study will be useful for the policy makers to take necessary measures to attract their potential customers and help them to solve their problems. Subsequently, this study recommends to the banks of Pakistan to observe and understand the business needs of the SMEs and provide sufficient finance and consultancy to ensure their effective business development. Training and development programs are also very important for the staff of banks to become professional, friendly, courteous, and responsive to the SMEs requirements and meet the requirement of the market. Like other studies this study also has limitations for example, the limited size and cross sectional nature. Therefore, the generalizability of this study is confined. Future researchers can use more sample size in various sectors and areas.

\section{References}

Akhtar, M. H., \& Nishat, M. (2002). X-efficiency analysis of commercial banks in Pakistan: A preliminary investigation [with Comments]. The Pakistan Development Review, 567-580.

Almossawi, M. (2001). Bank selection criteria employed by college students in Bahrain: an empirical analysis. International Journal of Bank Marketing, 19(3), 115-125.

Blankson, C., Omar, O. E., \& Cheng, J. M. S. (2009). Retail bank selection in developed and developing countries: A cross- national study of students' bank- selection criteria. Thunderbird International Business Review, 51(2), 183-198.

Boyd, W. L., Leonard, M., \& White, C. (1994). Customer preferences for financial services: an analysis. International Journal of Bank Marketing, 12(1), 9-15.

Chin, W. W. (1998). The partial least squares approach to structural equation modeling. Modern methods for business research, 295(2), 295-336.

Chin, W. W. (2010). How to write up and report PLS analyses Handbook of partial least squares (pp. 655-690): Springer.

Denton, L., \& Chan, A. K. (1991). Bank selection criteria of multiple bank users in Hong Kong. International Journal of Bank Marketing, 9(5), 23-34.

Devlin, J. F., \& Gerrard, P. (2004). Choice criteria in retail banking: an analysis of trends. Journal of Strategic Marketing, 12(1), 13-27.

Falk, R. F., \& Miller, N. B. (1992). A primer for soft modeling: University of Akron Press. 
Fernandes, V. (2012). (Re) discovering the PLS approach in management science. M@n@gement, 15(1).

Fornell, C., \& Larcker, D. F. (1981). Evaluating structural equation models with unobservable variables and measurement error. Journal of marketing research, 39-50.

Gerrard, P., \& Cunningham, B. (2001). Bank service quality: a comparison between a publicly quoted bank and a government bank in Singapore. Journal of Financial Services Marketing, 6(1), 50-66.

Götz, O., Liehr-Gobbers, K., \& Krafft, M. (2010). Evaluation of structural equation models using the partial least squares (PLS) approach Handbook of partial least squares (pp. 691-711): Springer.

Hafeezur, R., \& Saima, A. (2008). An Empirical Analysis of the Determinants of Bank Selection in Pakistan: A Customer Review. Pakistan Economic and Social Review, 46(2), 147-155.

Hair, J. F., Ringle, C. M., \& Sarstedt, M. (2011). PLS-SEM: Indeed a silver bullet. Journal of Marketing theory and Practice, 19(2), 139-152.

Hair, J. F., Sarstedt, M., Ringle, C. M., \& Mena, J. A. (2012). An assessment of the use of partial least squares structural equation modeling in marketing research. Journal of the academy of marketing science, 40(3), 414-433.

Hair, J. F., William, C. B., Barry, J. B., \& Anderson, R. E. (2010). Multivariate Data Analysis (7th ed.). NJ, USA 2010: PrenticeHall EnglewoodCliffs

Hair Jr, J. F., Hult, G. T. M., Ringle, C., \& Sarstedt, M. (2016). A primer on partial least squares structural equation modeling (PLS-SEM): Sage Publications.

Henseler, J., Ringle, C. M., \& Sarstedt, M. (2015). A new criterion for assessing discriminant validity in variance-based structural equation modeling. Journal of the academy of marketing science, 43(1), 115-135.

Holstius, K., \& Kaynak, E. (1995). Retail banking in Nordic countries: the case of Finland. International Journal of Bank Marketing, 13(8), 10-20.

Kaynak, E., \& Kucukemiroglu, O. (1992). Bank and product selection: Hong Kong. International Journal of Bank Marketing, 10(1), 3-16.

Khalique, M., Bontis, N., Jamal, A. N. b. S., \& Isa, A. M. (2015). Intellectual capital in small and medium enterprises in Pakistan. Journal of Intellectual Capital, 16(1), 224-238.

Khalique, M., Bontis, N., Shaari, J. A. N. B., Yaacob, M. R., \& Ngah, R. (2018). Intellectual capital and organisational performance in Malaysian knowledgeintensive SMEs. International Journal of Learning and Intellectual Capital, 15(1), 20-36.

Khalique, M., Shaari, J. A. N. B., \& Isa, A. H. B. M. (2014). Determining the influence of intellectual capital on the organisational performance of banking sector in Kelantan, Malaysia. International Journal of Learning and Intellectual Capital, 11(4), 306-319.

Khalique, M., Shaari, N., Abdul, J., Isa, A. H. B. M., \& Samad, N. B. (2013). Impact of intellectual capital on the organizational performance of Islamic banking sector in Malaysia. Asian Journal of Finance and Accounting, 5(2), 75-83. 
Kheng, L. L., Mahamad, O., Ramayah, T., \& Mosahab, R. (2010). The impact of service quality on customer loyalty: A study of banks in Penang, Malaysia. International journal of marketing studies, 2(2), 57.

King, R. G., \& Levine, R. (1993). Finance and growth: Schumpeter might be right. The quarterly journal of economics, 108(3), 717-737.

Kumari, J. (2017). Role of Banks in the Development of Indian Economy. Imperial Journal of Interdisciplinary Research, 3(1), 740-743.

Rao, S., \& Sharma, R. (2010). Bank selection criteria employed by MBA students in Delhi: An empirical analysis. Journal of Business Studies Quarterly, 1(2), 5669

Rashid, M., Bhuiyan, A., \& Nishat, A. (2012). Bank selection criteria in developing country: Evidence from Bangladesh. Asian Journal of Scientific Research, 5(2), 58-69.

Rehman, H. U., \& Ahmed, S. (2008). An empirical analysis of the determinants of bank selection in Pakistan: A customer view. Pakistan Economic and Social Review, 147-160.

Saad, N. M. (2012). Comparative analysis of customer satisfaction on Islamic and conventional banks in Malaysia. Asian Social Science, 8(1), 73.

Sadiq, M., Khan, S., \& Abdur, R. K. M. (2014). Bank selection criteria: a study in Malaysia. Актуальні проблеми економіки(7), 429-435.

Sekaran, U., \& Bougie, R. (2016). Research methods for business: A skill building approach: John Wiley \& Sons.

Siddique, M. (2015). Bank Selection Influencing Factors: A Study on Customer Preferences with Reference to Rajshahi City. Asian Business Review, 1(1), 8087.

Thwaites, D., \& Vere, L. (1995). Bank selection criteria-a student perspective. Journal of Marketing Management, 11(1-3), 133-149.

Zaidi, E. (2018). Karandaaz aims over 600 SMEs in its credit portfolio by 2019. Retrieved June 23, 2018 from https://www.thenews.com.pk/print/305706karandaaz-aims-over-600-smes-in-its-credit-portfolio-by-2019, from The News

Zulfiqar, B., Arshad, H. M., Fareed, Z., Shahzad, F., \& Hussain, S. (2014). Criteria of selecting bank in Pakistani banking sector: Study of banking customers in Sahiwal, Pakistan. International Journal of Managing Value and Supply Chains, 5(4), 19. 